\title{
Construção de um interferômetro de Michelson-Morley com materiais de baixo custo
}

\section{Cristian Costa e Silva} cristian.costa@upf.br 0000-0001-6389-2606

niversidade de Passo Fundo, Passo Fundo, Rio Grande do Sul, Brasil

\section{Alisson Cristian Giacomelli} alissongiacomelli@upf.b

000-0002-8490-4132 Universidade de Passo Fundo, Passo Fundo, Rio Grande do Sul, Brasil.

Carlos Ariel Samudio Pérez samudio@upf.br

0000-0002-1976-9886

Universidade de Passo Fundo, Passo Fundo, Rio Grande do Sul, Brasil.

\section{Barbara Locatelli da Silva} 115047@upf.br

000-0002-6040-5902

Universidade de Passo Fundo, Passo Fundo, Rio Grande do Sul, Brasil.

\section{RESUMO}

O presente trabalho constitui-se no relato da realização de uma atividade experimental relacionada ao conteúdo de ondulatória e Física Moderna. Para a atividade optou-se pela construção de uma versão do interferômetro de Michelson-Morley. O principal objetivo é que o equipamento possa servir como alternativa de uso com alunos, tanto para professores do Ensino Médio como, também, do Ensino Superior. Este trabalho traz, inicialmente, discussões sobre alguns aspectos históricos relativos ao desenvolvimento do interferômetro em sua versão original. Posteriormente, é apresentada uma proposta de montagem do equipamento com materiais alternativos e de fácil aquisição. Por meio da utilização do equipamento, pode-se observar o padrão de interferência entre dois feixes e a sua dependência em relação às distâncias percorridas por cada um deles. $O$ equipamento pode ser utilizado amplamente utilizado no ensino de Física, tanto para discutir o fenômeno de interferência entre ondas luminosas, como para introduzir o conteúdo de relatividade restrita.

PALAVRAS-CHAVE: Ensino de Física. Experimentação. Interferômetro de MichelsonMorley. 


\section{INTRODUÇÃO}

Ensinar ciências não diz respeito a apenas depositar conteúdos de forma sistemática, mas de fazer os alunos refletirem sobre esses conteúdos, relacionando-os, tanto com seu cotidiano, como com aspectos gerais da sociedade e do desenvolvimento da ciência. Uma ferramenta que pode ser utilizada para fomentar tais reflexões são as atividades experimentais. No entanto, mesmo que se tenha clareza sobre a potencialidade da realização de tais atividades em sala de aula, nem sempre essas são utilizadas pelos professores. Essa escassez no uso de atividades experimentais pode estar relacionada a diversos fatores, tais como: preparação insuficiente dos professores, falta de acesso a materiais e propostas metodológicas, entre outros. De acordo com Rosa (2003, p. 97), "a discordância entre a importância dada pelos docentes, e a pouca realização destas atividades na prática pedagógica pode ser associada à falta de clareza que se tem hoje quanto ao papel do laboratório no processo ensino-aprendizagem".

Os desafios para a realização das atividades experimentais ampliam-se quando se solicita aos alunos que construam o experimento. Há que se considerar, também, que o processo de aprendizagem dos conceitos científicos é bastante complexo e envolve múltiplas dimensões, exigindo que o trabalho investigativo do aluno assuma várias formas que possibilitem o desencadeamento de distintas ações cognitivas. Algumas de tais ações consistem na manipulação de materiais, questionamentos, direito à investigação e ao erro, observação e comunicação, verificação das hipóteses levantadas, entre outras.

A experiência se encaixa num processo não de saber-fazer, mas de reflexão sistemática, de criatividade e mesmo de invenção. Hodson (1990) considera que o trabalho experimental tal como é conduzido em muitas escolas é de concepção pobre, confuso e não produtivo. Para ele, muitos professores acreditam que o trabalho experimental ensina os estudantes sobre o que é ciência e a sua metodologia, o que descaracteriza a finalidade didática da experimentação em sala de aula.

Utilizar atividades investigativas como ponto de partida para desenvolver a compreensão de conceitos é uma forma de levar o aluno a participar de seu processo de aprendizagem, a sair de uma postura passiva, a perceber e a agir sobre o seu objeto de estudo, relacionando-o com o cotidiano, buscando as causas dessa relação e procurando uma explicação causal para o resultado de suas ações e/ou interações.

Por meio da observação e da ação, que são pressupostos básicos para uma atividade investigativa, pode-se levar os alunos a perceberem que o conhecimento científico se dá por meio de uma construção, mostrando, assim, o aspecto dinâmico e aberto desse, possibilitando que o aluno participe de sua construção. Essa concepção vai em contraponto ao que descrevem alguns livros de Ciências, em que o "método científico" é mostrado como algo fechado, uma sequência lógica e rígida, composta de passos a serem seguidos, fazendo com que o aluno pense que a ciência é fechada, criada a partir da observação, somente dessa. 
específicas, permitindo ao aluno lidar com fenômenos naturais e tecnológicos presentes no seu cotidiano. Para isso, o uso de ferramentas didáticas alternativas, como a experimentação, é um método de ligação de conceitos físicos com o cotidiano do estudante.

Por considerar que as estratégias de ensino e metodologias utilizadas na abordagem de conteúdos pertencem aos domínios do professor, como discute Chevallard; Johsua (1991), a pesquisa no ensino de Física tem direcionado enfoques para o uso de estratégias de ensino que facilitem a compreensão dos conceitos e fenômenos dessa área por parte dos estudantes. Nesse sentido, a realização de atividades experimentais pode se mostrar muito eficiente em vários momentos do processo de ensino e aprendizagem. Com base nessas considerações, fica justificada a proposta deste trabalho, pois visa à realização de uma atividade experimental direcionada ao ensino de Física, que poderá ser efetivada tanto no ensino médio como no superior, visto que tal atividade tem a potencialidade de servir como uma ferramenta que pode tornar mais compreensível um determinado conteúdo.

Diante do exposto, o principal objetivo do presente trabalho consiste em apresentar uma proposta de construção de um interferômetro de MichelsonMorley para que esse possa servir como ferramenta a ser utilizada por professores de Física. A metodologia de utilização do equipamento fica a critério do professor e de acordo com suas convicções no que diz respeito ao processo de ensino e aprendizagem. Nesse sentido, o trabalho representa apenas uma sugestão de roteiro-guia, mas que pode ser adaptado e modificado de acordo com as possibilidades e os objetivos do professor.

No que diz respeito à sua estrutura, o artigo traz, inicialmente, algumas discussões sobre o uso das atividades experimentais no ensino de ciências. Na sequência, são feitas considerações sobre aspectos históricos relacionados ao desenvolvimento do interferômetro em sua versão original. Por fim, antes das considerações finais, é apresentada uma proposta de montagem do equipamento, assim como, uma proposta de uso metodológico para esse.

\section{CONSIDERAÇÕES SOBRE A UTILIZAÇÃO DO INTERFERÔMETRO NA HISTÓRIA DA CIÊNCIA}

Em nosso cotidiano, tudo aquilo que nossos olhos percebem está condicionado a uma informação que se propaga por meio da luz. A invariância da velocidade da luz é uma das leis mais bem estabelecidas da Física e resulta em consequências surpreendentes no âmbito da relatividade restrita de Einstein. $O$ estudo da natureza e das características da luz permite uma compreensão mais apurada, tanto do mundo subatômico como do universo em larga escala. São inúmeras as aplicações tecnológicas relacionadas ao estudo da luz, desde um simples celular, um aparelho de micro-ondas, o funcionamento de equipamentos de GPS (do nome em inglês Global Positioning System), até os estudos de astronomia e astrofísica. Nesse sentido, a compreensão da natureza e das características da luz se mostra de fundamental importância no intuito de relacionar o conteúdo trabalhado na sala de aula com o cotidiano dos estudantes 
e com os avanços científicos e tecnológicos que ocorrem diariamente em nossa sociedade.

O entendimento sobre a natureza da luz, durante muito tempo, intrigou os cientistas. Isaac Newton (1642-1726) acreditava que a luz era formada por pequenas partículas, o que culminou no modelo corpuscular da luz. Tal modelo considerava que as partículas de luz emergiam da fonte e que sua propagação era retilínea. A concepção de Newton para a natureza da luz era satisfatória, pois explicava com razoável precisão os fenômenos conhecidos até então.

Já Christiaan Huygens (1629-1695) propôs que a luz consistia em um fenômeno ondulatório. Nesse sentido, assim como as ondas mecânicas, necessitava de um meio para se propagar. As ondas eletromagnéticas não se propagariam no vácuo, e, sim, em um meio que passou a ser chamado de "éter". Essa substância estaria presente em todos os lugares, inclusive no vácuo do espaço "vazio". Com base no exposto, Huygens e seus seguidores acreditavam que a luz se transmitia por intermédio do éter como uma onda sonora se propaga em um meio material.

No século XIX, o escocês James Clerk Maxwell (1831-1879), publicou sua obra "Um tratado sobre eletricidade e magnetismo", na qual reuniu um conjunto de equações que descreviam a luz como uma onda eletromagnética. Maxwell determinou a velocidade dessas ondas e chegou ao resultado aproximado de $3 \mathrm{x}$ $108 \mathrm{~m} / \mathrm{s}$. Esse fato remete à ideia de que a luz se desloca a uma velocidade finita, porém, muito alta. No entanto, esse resultado teve como consequência um problema teórico muito grave, a saber: se a velocidade da luz é finita, em relação a que essa velocidade deve ser medida? Até então, segundo a mecânica clássica, o movimento sempre foi considerado relativo o que resulta no fato de o mesmo corpo poder apresentar velocidades diferentes dependendo do referencial em que se analisa o movimento. Aplicando essa mesma ideia à teoria eletromagnética de Maxwell, conclui-se que um observador pode medir velocidades diferentes para um feixe de luz, dependendo do seu estado de movimento relativo. Inclusive ele pode igualar a sua velocidade a do feixe de luz, o que causa um resultado conflitante sob o ponto de vista físico. O conflito reside no fato de que, segundo a teoria de Maxwell, um feixe de luz é constituído de um campo elétrico variável e um campo magnético variável, se um determinado observador estiver em repouso relativo a um feixe de luz o que ele verá serão dois campos estáticos. Porém, segundo a teoria de Maxwell, tais campos são impossíveis. Esse problema remete ao experimento de surfagem no raio de luz apontado por Einstein ainda quando era jovem, anos antes de elaborar a teoria da relatividade restrita.

Para solucionar tal problema, foi sugerido que a luz deveria se propagar num meio chamado de éter luminoso ou éter luminífero. O éter luminífero seria uma espécie de fluido infinito e menos espesso que os gases mais leves, perfeitamente elástico, invisível e indetectável, preenchendo todos os espaços do universo, tanto interplanetários quanto intermoleculares. Nesse sentido, a velocidade da luz deveria ser constante em relação ao éter, porém podendo variar em relação a outros referenciais, o que, em princípio, solucionava o problema do experimento mental da surfagem no raio de luz.

Para detectar o vento do éter, em 1881, o cientista alemão Albert Abraham Michelson (1852-1931) construiu um experimento chamado interferômetro. O princípio utilizado por Michelson foi o de que se a teoria do éter fosse aplicável na 
prática, então, quando a Terra se efetua, em seu movimento de rotação, ela se movimentaria em relação ao éter. Nesse sentido, considerando que a luz tem uma velocidade constante em relação a essa substância, dever-se-ia detectar uma discrepância entre as medidas da velocidade da luz em relação à Terra, quando essas fossem realizadas na mesma direção do movimento de rotação do planeta e, depois, na direção perpendicular. Porém, nenhuma diferença foi detectada, o que, inicialmente, justificou-se com o argumento de que o equipamento era sensível demais, a ponto de ser desregulado até mesmo com a vibração proveniente de movimentos vindos da rua, determinando os resultados negativos.

Em 1887, Michelson e o norte-americano Edward Williams Morley (18381923), retomaram os estudos sobre o interferômetro, reformulando esse equipamento em Cleveland, tornando-o muito mais aprimorado do que o anterior, podendo-se desprezar qualquer influência externa, aumentando, significativamente, a confiabilidade da experiência.

A ideia do interferômetro era medir o padrão de interferência da luz quando se propagava em diferentes direções. O interferômetro tinha dois feixes de luz perpendiculares entre si, que eram refletidos por espelhos. Qualquer diferença na propagação dos feixes resultaria num padrão destrutivo de interferência. Já que a Terra se movimentaria através do éter, previa-se que a velocidade de propagação da luz em relação à Terra fosse diferente em direções diferentes. Se a hipótese do éter estivesse correta, então, o feixe que apontasse na direção de propagação da Terra com relação ao éter se moveria mais rapidamente do que o feixe perpendicular, formando um padrão de interferência destrutiva. Porém, os resultados persistiam em ser negativos, não confirmando a presença de tal fluido.

\section{REALIZAÇÃO DO EXPERIMENTO E RESULTADO OBTIDO}

O interferômetro de Michelson-Morley é um importante dispositivo experimental que utiliza interferência entre feixes de luz para realizar medições precisas de amplitudes de onda em distâncias muito pequenas. Também pode ser utilizado para determinar índices de refração de um meio específico, considerando a variação de velocidade de propagação em meios homogêneos e transparentes.

Um feixe de luz proveniente de uma fonte, no caso um laser, incide em um espelho semi-refletor, revestido com uma fina camada de prata. Após a passagem pelo divisor de feixe, as ondas são divididas em duas partes que viajam em direções perpendiculares entre si. Cada um desses feixes é refletido pelos espelhos posicionados nas extremidades do interferômetro, voltando ao ponto onde foram divididos, voltando a combinar-se, formando novamente apenas um feixe que passa por uma lente e incide em um anteparo. No anteparo da Figura 3, pode-se observar o padrão de interferência proveniente da recombinação do feixe. 


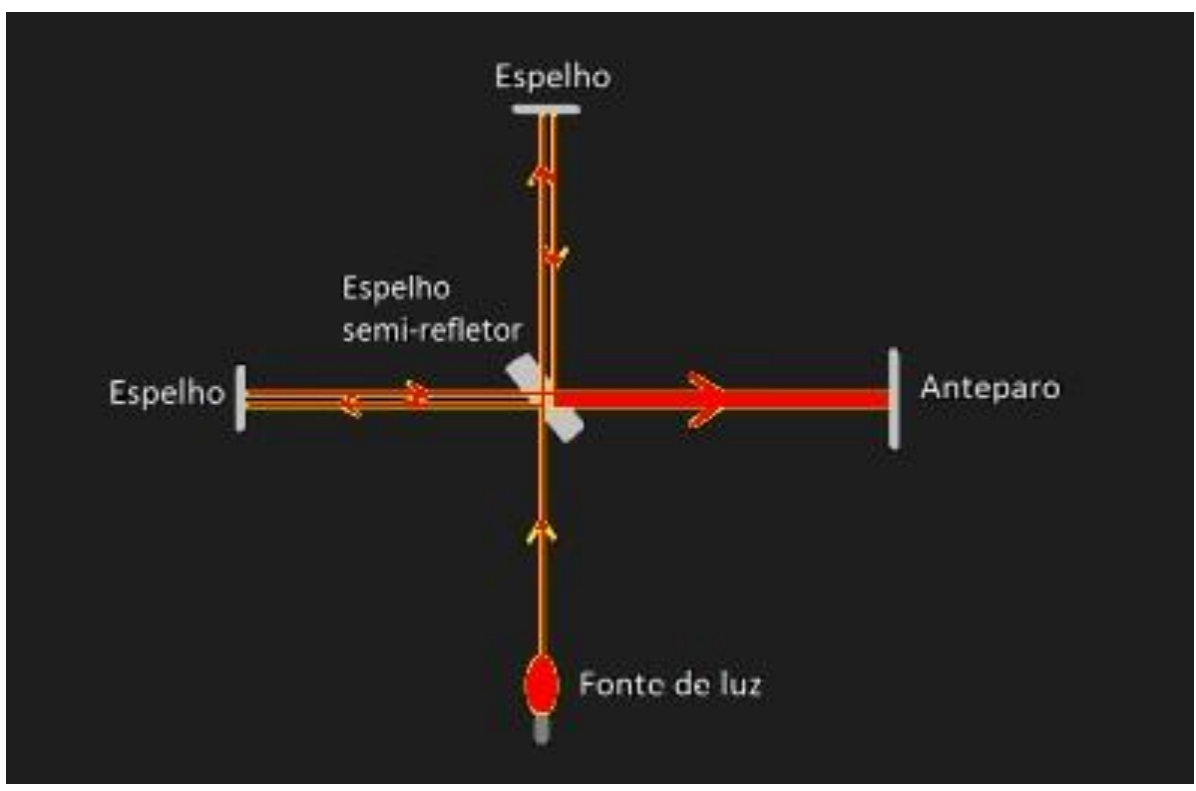

Fonte: dos autores, 2016.

Pode-se averiguar que, os feixes de luz, ao se encontrarem novamente após a passagem pelo espelho semi-prateado irão gerar um padrão de interferência que pode ser construtivo ou destrutivo, dependendo de como ocorre o encontro dos dois feixes.

Caso os feixes se recombinem em fase, a interferência será construtiva, se estiverem fora de fase, a interferência será destrutiva. A Figura 2 traz explicação simples de como ocorre a interferência construtiva e destrutiva entre duas ondas.

Figura 2 - Modelo conceitual interferências

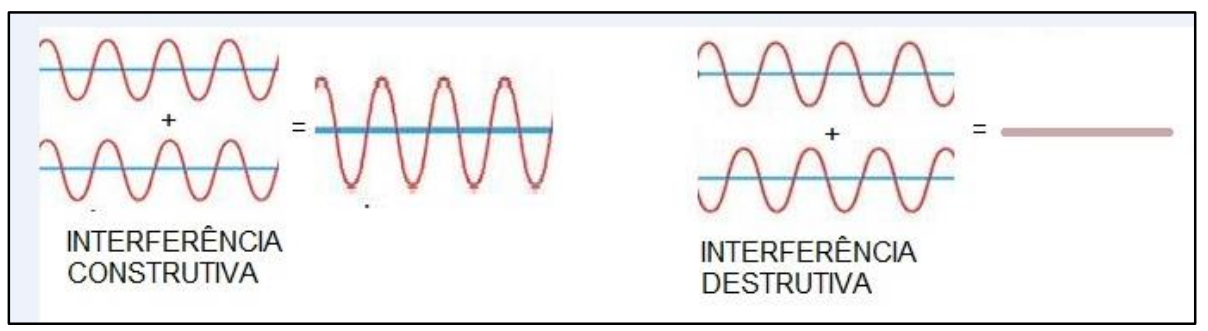

Fonte: dos autores, 2016.

Por meio do interferômetro, quando os feixes de luz estão em fase, é possível se observar uma interferência construtiva evidenciada por franjas claras, enquanto que, quando os feixes estão fora de fase se observará uma interferência destrutiva caracterizada por franjas escuras. Por fim, a interferência dos dois feixes irá gerar um padrão de interferência caracterizado por um conjunto de franjas claras e escuras. Utilizando-se o arranjo experimental da Figura 8 pode-se observar esse padrão, que se encontra registrado na fotografia da Figura 3. 
Figura 3 - Padrão de franjas provenientes de experimento

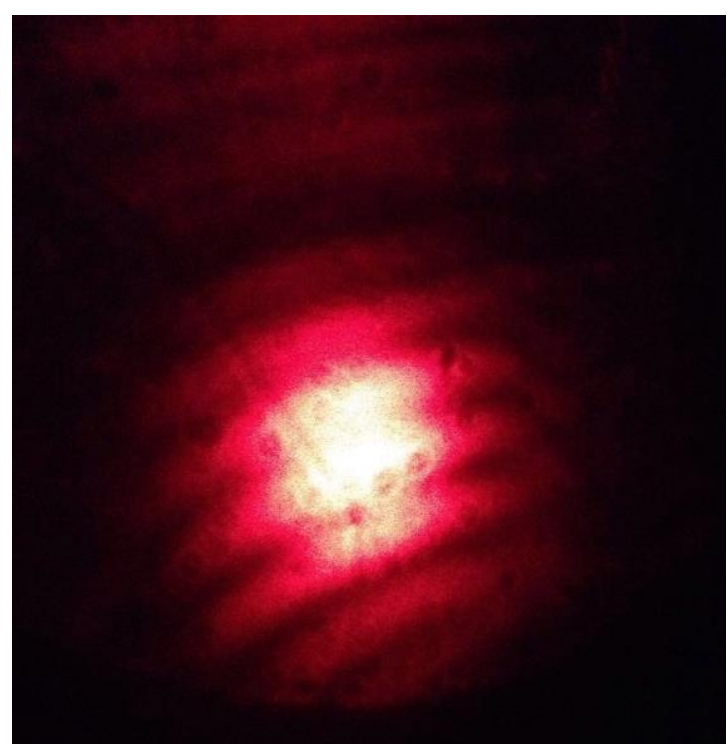

Fonte: dos autores, 2016.

Além do estudo dos fenômenos ópticos, o experimento pode ser utilizado em uma abordagem histórica para introduzir o conteúdo de relatividade restrita. 0 experimento é bastante sensível, sendo que o ajuste dos espelhos e da fonte deve ser realizado com bastante cuidado. Na experiência em questão, utilizou-se massa de modelar para os ajustes finos das posições dos elementos envolvidos, porém podem-se utilizar outros métodos desde que o ajuste possa ser feito com razoável precisão.

\section{PROPOSTA DE CONSTRUÇÃO DO INTERFERÔMETRO}

O interferômetro constitui-se em um aparelho que não é muito utilizado nas salas de aula, principalmente no que diz respeito à educação básica. A não utilização desse equipamento pode ser justificada por alguns fatores: primeiro, para a aquisição de um equipamento comercial é necessário um investimento relativamente elevado, pela precisão e materiais específicos utilizados em sua construção; segundo, a construção de um exemplar do equipamento apresenta um grau elevado de dificuldade. Devido à estabilidade que se deve ter no aparelho, evitando ao máximo as perturbações mecânicas, o experimento é, geralmente, construído a partir de bases metálicas. Por outro viés, para um melhor funcionamento são necessários espelhos de primeira face. Esses itens, comercialmente, apresentam custo elevado, assim como acontece com o espelho de meia face ou o espelho semi-prateado, cuja função é dividir e recombinar o feixe.

O principal objetivo do presente trabalho é relatar uma proposta de construção de um interferômetro didático no intuito de baixar o seu custo e reduzir ao máximo as complicações na sua montagem, de tal forma que esse possa ser reproduzido e utilizado por professores da educação básica. Para isso, os materiais escolhidos para construção do equipamento são materiais alternativos e de baixo custo, sendo que apresentam, ainda, a possibilidade de substituição por outros de acordo com a disponibilidade e a habilidade de quem for reproduzir o experimento. Para a proposta de montagem apresentada neste trabalho foram 
utilizados os seguintes materiais: 5 tubos de PVC $19 \mathrm{~mm} \times 150 \mathrm{~mm}$; 5 tampões 19 mm; 1 tampão 50 mm; 1 chapa polionda de 900 x 900 mm; uma chapa polionda de 400 x 400 mm; uma caneta laser de diodo; uma lente de aproximação; massa de modelar, um pedaço retangular de vidro espesso 50 × $50 \mathrm{~mm} ; 2$ espelhos retrovisores de moto.

Os espelhos foram adquiridos num ferro velho e apresentam a primeira face espelhada, evitando dupla reflexão. Dos espelhos retrovisores foram retirados dois pedaços aproximadamente planos. Para isso, eles foram levados a uma vidraçaria, onde foram cortados.

O vidro, adquirido numa vidraçaria, com refletância aproximada de $50 \%$, será utilizado como divisor de feixe. Para testar a refletância, foram utilizados a caneta laser e um celular com sensor medidor de intensidade luminosa. A Figura 4 retrata os materiais.

Figura 4 - Materiais

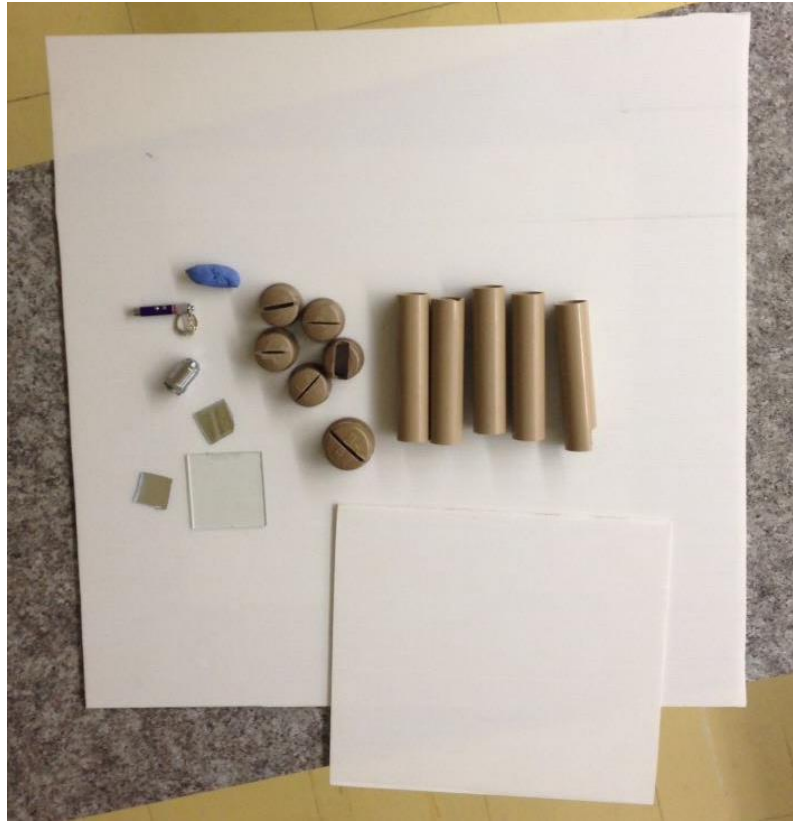

Fonte: dos autores, 2016.

A seguir, na Figura 5, é apresentada uma proposta referente aos passos para a construção e a montagem do interferômetro. 


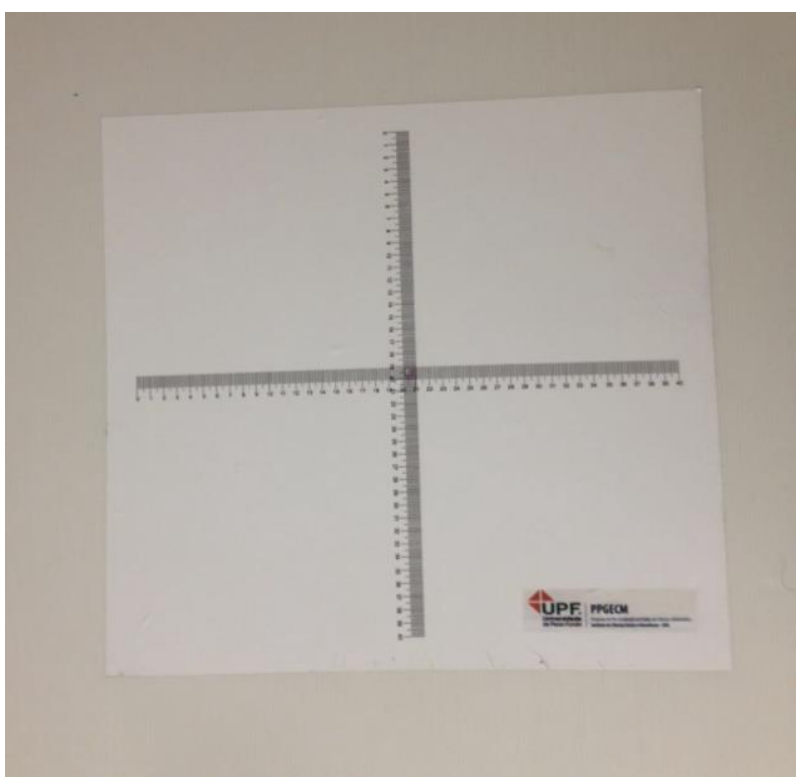

Fonte: dos autores, 2016.

A base do equipamento foi construída fixando a chapa de polionda numa base de madeira, para reduzir perturbações mecânicas. Sobre a chapa polionda foi fixada uma escala milimétrica para facilitar o ajuste das distâncias dos suportes em relação ao espelho semi-prateado, conforme consta na Figura 6.

Figura 6 - Anteparo

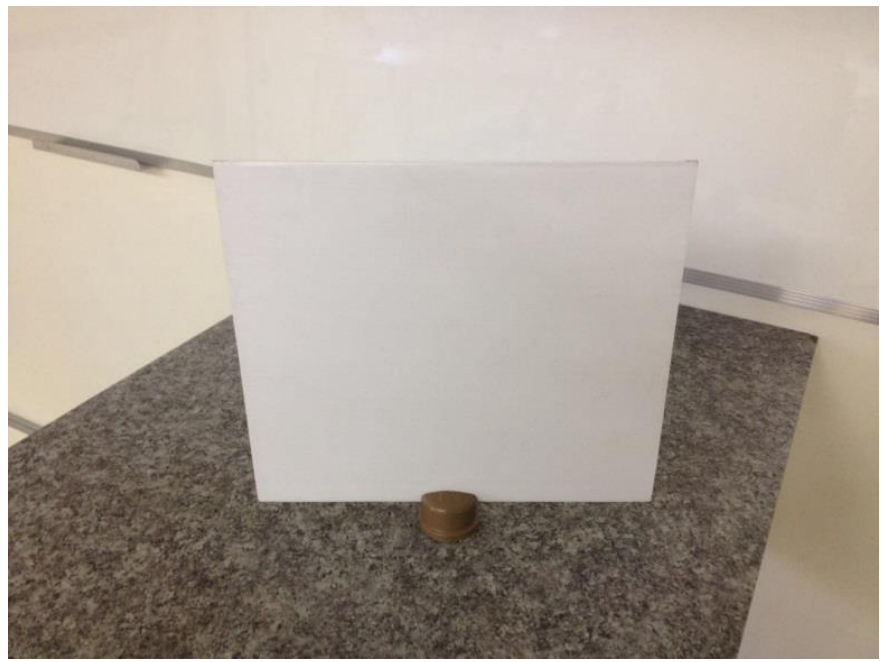

Fonte: dos autores, 2016.

O anteparo foi construído utilizando um pedaço quadrado da chapa de polionda fixado a um suporte construído com um tampão de PVC $50 \mathrm{~mm}$, com o intuito de visualizar o padrão de interferência dos feixes. A Figura 7 ilustra essa etapa. 
Figura 7 - Suporte espelhos, divisor de feixe, lente de aumento e fonte de luz

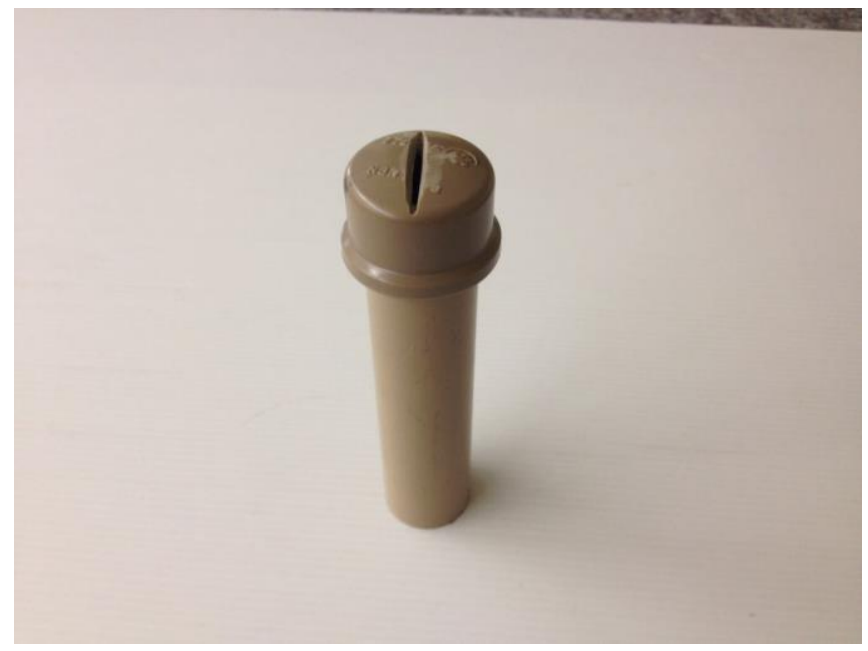

Fonte: dos autores, 2016.

Os suportes para os espelhos, lente de aumento e divisor de feixe foram construídos usando tampões de PVC de 19mm, nos quais foram feitas, uma a uma, ranhuras lineares com um arco de serra para encaixar os espelhos. Já o suporte da caneta laser de diodo necessita de uma abertura um pouco maior para sua fixação. Os tampões foram fixados cada um sobre um pedaço de cano de PVC de $150 \mathrm{~mm}$ de comprimento e a lente, espelhos, laser e divisor de feixes foram fixados aos suportes de PVC, utilizando massa de modelar.

Figura 8 - Arranjo experimental

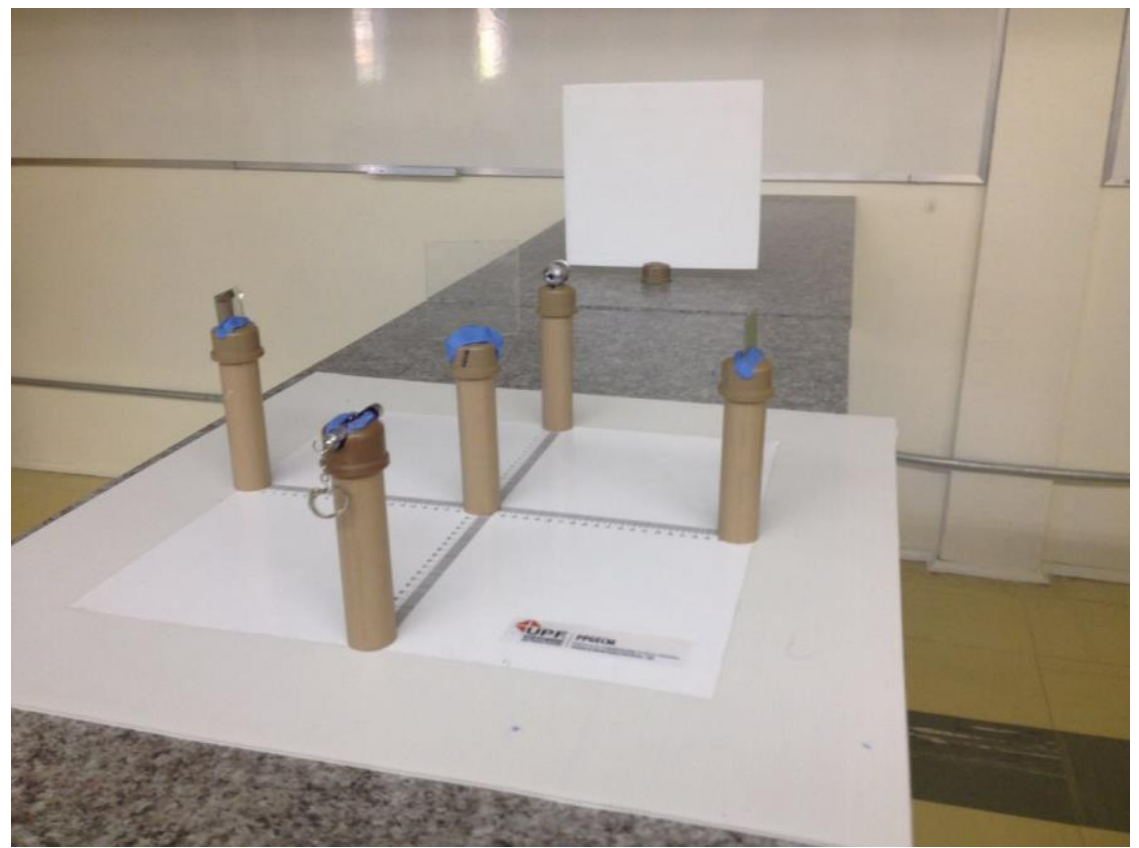

Fonte: dos autores, 2016.

A montagem faz-se sobre a base de chapa polionda, colocando os espelhos em paralelo, juntamente com a fonte de luz e a lente de aumento em paralelo, nas extremidades da escala milimétrica. $O$ divisor de feixes foi colocado no suporte 
sobre a escala milimétrica (Figura 8), de forma que ficou com uma inclinação aproximada de 45 em relação ao eixo paralelo à fonte de luz.

\section{PROPOSTA DE REALIZAÇÃO DA EXPERIÊNCIA EM SALA DE AULA}

Propõem-se, no presente estudo, que a experiência exposta pode ser realizada a fim de abordar dois conteúdos distintos. Pode-se utilizar o equipamento tanto para o estudo de fenômenos de óptica e ondulatória, assim como para trabalhar a teoria da relatividade restrita de Einstein. Sugere-se que o experimento seja realizado de forma demonstrativa, instigando os estudantes a argumentarem sobre a sua montagem e sobre os resultados obtidos. A metodologia propriamente dita fica a critério do professor que for realizar a experiência e de acordo com as suas convicções pedagógica. A experiência pode ser utilizada como elemento introdutório do conteúdo, durante a abordagem desse ou como fechamento, essa decisão cabe ao professor e deve estar respaldada pelo planejamento das aulas por parte do docente. Considerando a sugestão de que o experimento pode ser utilizado na abordagem de dois conteúdos distintos, a descrição da proposta de realização da atividade também será feita em duas partes.

Inicialmente, será descrita uma proposta de utilização do equipamento relacionada ao conteúdo de óptica. Primeiramente, o professor precisa regular o equipamento, esse momento pode ser uma ação colaborativa, em que os estudantes podem auxiliar interagindo com o equipamento, com o professor e com os colegas. Alguns elementos importantes na regulagem do equipamento são o posicionamento dos espelhos, da lente, da fonte e do anteparo, a inclinação dos espelhos e do semi-espelho também é muito sensível e precisa ser ajustada com cuidado. Podem-se realizar várias demonstrações de óptica com o auxílio do interferômetro. Por exemplo, pode-se mostrar como o diagrama de interferências é sensível a vibrações do meio. Para tanto, deve-se bater, levemente, na mesa, por exemplo.

Também pode-se demonstrar como o diagrama é perturbado ao alterar as propriedades do ar no qual os feixes se propagam. Para isso, o professor pode utilizar uma chama de vela, ou qualquer outra fonte de calor. Colocando-se a chama próxima ao espaço onde viaja um dos feixes, altera-se o índice de refração do ar, devido ao aumento de temperatura provocado. Alterando as propriedades do ar, o diagrama será perturbado também.

Quando os espelhos estiverem com distâncias iguais e perpendiculares, as franjas passam a ser circulares, formando um campo de interferência uniforme. Mover as posições de um dos espelhos, alterando a distância percorrida por um dos feixes, faz com que ocorram mudança no resultado, tornando as franjas lineares. Quanto maior a distância dos espelhos refletores, mais círculos concêntricos de interferência serão observados.

Outro conteúdo que pode ser contemplado utilizando-se a experiência de Michelson-Morley, trata-se da teoria da relatividade restrita de Einstein. A teoria de Einstein é derivada de dois postulados fundamentais, o primeiro refere-se ao próprio princípio da relatividade galileno, porém generalizado para fenômenos da eletrodinâmica. O segundo postulado de Einstein diz o seguinte: "[...] a luz, no 
espaço vazio, se propaga sempre com uma velocidade determinada, independentemente do estado de movimento da fonte luminosa" (EINSTEIN, 1958). Esse postulado estabelece a invariância da velocidade da luz e, na época que foi proposto por Einstein, em 1905, resolveu o problema existente entre a mecânica clássica e o eletromagnetismo, tornando desnecessária a existência do éter luminoso.

O experimento de Michelson-Morley foi desenvolvido com o objetivo de detectar o éter, justificando a proposta de sua existência. A existência do éter na época resolvia em partes o problema da mecânica clássica com o eletromagnetismo, porém, sua existência nunca foi observada. Einstein tinha conhecimento do resultado negativo da experiência, contudo, o segundo postulado, assim como toda a teoria da relatividade restrita, foi elaborado a fim de resolver um problema teórico e não foi, simplesmente, uma consequência do resultado experimental obtido por Michelson-Morley. De fato, a teoria da relatividade restrita explica, de forma não intencional, o resultado negativo do experimento de Michelson-Morley, porém, historicamente, é inverídico afirmar que tais resultados serviram como base para o desenvolvimento da teoria por Einstein, visto que, em seu artigo de 1905, ele nem sequer os menciona (SILVEIRA; PEDUZZI, 2006).

Com base no exposto, referente ao surgimento da teoria da relatividade restrita, a atividade apresentada neste artigo pode ser desenvolvida, também, para se trabalhar tal conteúdo. Nesse sentido, sugere-se uma abordagem relacionada à história da ciência, em que se pode fomentar discussões e reflexões com os estudantes sobre alguns eventos que estavam ocorrendo no meio científico na época. Por meio de uma abordagem histórica, pode-se destacar qual foi a causa e o objetivo do desenvolvimento da experiência por Michelson-Morley, a motivação e o entendimento de Lorentz; Einstein; Miknkowski sobre a contração das distâncias e a dilatação do tempo, assim como, de que forma Einstein resolveu o problema com o seu segundo postulado e a consequente formulação da teoria da relatividade restrita.

\section{CONSIDERAÇÕES FINAIS}

Em muitos casos a visualização (mesmo que de forma indireta) de um determinado fenômeno pode ser um fator crucial para o seu entendimento por parte dos estudantes, assim como no sentido de fomentar discussões entre os membros do grupo. Em ambos os aspectos, a atividade realizada mostrou significativa potencialidade, levando em consideração os fatores históricos relacionados ao experimento, visto que foi possível observar com bastante clareza o padrão de interferência. Outro aspecto importante a se considerar foi a possibilidade verificada em se montar o equipamento com razoável facilidade e com materiais de fácil aquisição.

Para o desenvolvimento do experimento optou-se pela utilização de materiais alternativos e de baixo custo, podendo-se obter um resultado bastante satisfatório. Esse resultado demonstra a facilidade com que tal equipamento pode ser reproduzido nas escolas. Alguns aspectos do equipamento ainda precisam ser 
um tempo elevado até que se consiga regular o equipamento, a fim de observar o padrão de interferência, no entanto, isso não foi um fator impeditivo para a realização da atividade. 


\title{
CONSTRUCTION OF A MICHELSON -MORLEY INTERFEROMETER WITH LOW COST OF MATERIALS
}

\begin{abstract}
This work constitutes the report of the completion of an experimental activity related to the content of wave and Modern Physics. For activity we chose to build a version of the Michelson-Morley interferometer. The main objective is that the equipment can serve as an alternative for teachers, both of high school, and higher education can use it with their students. This work initially brings discussions about some historical aspects of the development of the interferometer in its original version. Later presents an equipment mounting proposal with alternative materials and easy to purchase. Through the use of the machine can observe the interference pattern between the two beams and its dependence on the distance covered by each of them. The equipment can be used both in high school and higher education to discuss the phenomenon of interference between light waves, as well as to introduce the relativity of content.
\end{abstract}

KEYWORDS: Michelson interferometer. Experimentation. Physics Teaching. 


\section{REFERÊNCIAS}

BRASIL. Ministério da Educação, Secretaria de Educação Básica. Orientações curriculares para o ensino médio: ciências da natureza, matemática e suas tecnologias. Brasília: Ministério da Educação, Secretaria de Educação Básica, 2006.

CHEVALLARD, Y.; JOHSUA, M-A. La transposition didatique: du savoir savant au savoir enseigné. Paris, La Pensée Sauvage. 1991.

LORENTZ, H. A.; EINSTEIN, A.; MIKNKOWSKI, H. O princípio da relatividade. Berna Lisboa: Fundação Clalouste Gulbenkian, 1958.

ROSA, C. T. W. Concepções teórico-metodológicas no laboratório didático de física na Universidade de Passo Fundo. Ensaio, v. 5, n. 2, p. 97, out. 2003.

SILVEIRA, F. L.; PEDUZZI, L. O. Q. Três episódios de descoberta científica: da caricatura empirista a uma outra história. Caderno Brasileiro de Ensino de Física, v. 23, n. 1, p. 26-52, abr. 2006.

HODSON, D. A critical look at practical work in school science. School Science Review, v. 70 n. 256, Association for Science Education, U.K. 1990.

DOI: 10.3895/rbect.v10n1.569

Como citar: SILVA, C. C. E; GIACOMELLI, A. C.; PÉREZ, C. A. S.; SILVA, B. L. Construção de um interferômetro de Michelson-Morley com materiais de baixo custo. Revista Brasileira de Ensino de Ciência e Tecnologia, v. 10, n. 1, 2017. Disponível em: <https://revistas.utfpr.edu.br/rbect/article/view/5691>. Acesso em: $x x x$.

Direito autoral: Este artigo está licenciado sob os termos da Licença Creative Commons-Atribuição 4.0 Internacional. 